\title{
ESTIMATIVA ECONÔMICA DA UTILIZAÇÃO DO BIOGÁS PARA GERAÇÃO DE ENERGIA ELÉTRICA NO PERÍMETRO IRRIGADO QUIXABINHA-MAURITI-CE
}

\author{
Erialdo de Oliveira Feitosa ${ }^{1}$, Daniel Albiero², Francisco Ronaldo Belem Fernandes ${ }^{3}$, Paulo Ricardo Alves dos \\ Santos $^{4}$, Carlos Alessandro Chioderoli ${ }^{5}$
}

\begin{abstract}
RESUMO
A demanda por fontes renováveis de energia tem aumentado nos últimos anos em função do crescimento econômico do país e pelo incremento de tecnologias no setor agropecuário brasileiro, contribuindo para a intensificação do uso de energia elétrica nas diversas atividades agrícolas. Um dos entraves que diminui significativamente a renda dos produtores familiares nos Perímetros Irrigados é o gasto com a energia elétrica utilizada para acionar os sistemas de irrigação, podendo chegar a 35\% do custo total de produção. Diante desta problemática, objetivou-se com este trabalho realizar um estudo de viabilidade econômica e estimativa de produção do biogás como fonte alternativa para a geração de energia elétrica a ser utilizada no Perímetro Irrigado. Foi utilizado o software RETScreen ${ }^{\circledR}$ para análise de viabilidade econômica e estimativa de produção, e os principais indicadores de viabilidade econômica foram o payback e a taxa interna de retorno. O estudo demonstrou ser economicamente viável a utilização do biogás proveniente dos resíduos vegetais e animais, como fonte de biomassa para geração de energia elétrica. Portanto, quanto maior a quantidade de matérias vegetais e dejetos de animais disponíveis aumenta-se a geração de energia elétrica e, consequentemente, a viabilidade econômica do sistema de geração.
\end{abstract}

Palavras-chaves: energia renovável, irrigação, viabilidade econômica.

\section{ABSTRACT \\ ECONOMIC ESTIMATE OF THE UTILIZATION OF BIOGAS FOR ELECTRICITY GENERATION IN IRRIGATED DISTRICT QUIXABINHA-MAURITI-CE}

The demand for renewable energy sources has grown in recent years in function of the economic growth of the country and technological advance in the Brazilian agricultural sector contributed to increased electricity use in various agricultural activities. One of barriers that significantly decrease the income of the family farmers in Irrigated Perimeters is the electricity expense used to activate irrigation systems, which can reach up to $35 \%$ of total production costs. Based on this problem, the present study sought to assess the economic viability and estimate biogas production as an alternative source for electricity generation to be used in the irrigation district. The RETScreen ${ }^{\circledR}$ software was used for analysis of economic viability and production estimates, and the main indicators of economic viability were payback period and the internal rate of return. The study indicated that utilization of biogas generated from plant and animal residues is an economically viable source for electricity generation. However, the greater the quantity of plant matter and bovine dejections available, greater is electricity generation and consequently the generation system is more economically viability.

Keywords: economic viability, irrigation, renewable energy.

\section{Recebido para publicação em 21/06/2014. Aprovado em 04/05/2015.}

1 - Tecnólogo em Irrigação e Drenagem, Doutorando em Eng. Agrícola na UFC, Fortaleza-CE, e-mail: erialdofeitosa5@gmail.com.br;

2 - Engenheiro Agrícola, Prof. Dr. Adjunto, UFC, Fortaleza - CE; e-mail: daniel.albiero@gmail.com;

3 - Engenheiro Agrônomo, Doutorando em Eng. Agrícola, na UFC, Fortaleza-CE, e-mail: ronaldoagroufc@gmail.com;

4 - Engenheiro Agrônomo, Mestrando em Eng. Agrícola na UFC, Fortaleza-CE, e-mail: paulo_ptg@hotmail.com;

5 - Engenheiro Agrônomo, Prof. Dr. Adjunto, UFC, Fortaleza - CE; e-mail: ca.chioderoli@ufc.br.

220 REVENG 220-227p. 


\section{INTRODUÇ̃̃O}

A energia é de fundamental importância no desenvolvimento sustentável rural, sendo imprescindível para todo o processo produtivo da agricultura no semiárido. Atualmente a economia mundial está passando por um período de mudanças na demanda de energia elétrica para as diversas atividades humanas, especificamente na produção agrícola que é continua e em crescimento no Brasil (ONS, 2011).

Com o advento da agricultura irrigada, observou-se o aumento produtivo das culturas, mas no Brasil esse modelo de agricultura ocupa apenas $10 \%$ da área total cultivada no país, e é responsável por aproximadamente $30 \%$ do valor bruto da produção agrícola (LARA, 2010). Porém, com a implantação dos projetos públicos de irrigação com infraestruturas de captação e adução, reservatórios, estações de bombeamento, canais e adutoras, fazse necessário a utilização da energia elétrica, por consequência, representa um forte componente nos custos totais, que podem chegar a $35 \%$ do custo da irrigação, reduzindo a margem de lucro do produtor (ANA, 2004).

No meio rural, os sistemas biointegrados, especificamente com aproveitamento de biomassa para fins energéticos, podem ser um meio facilitador para atingir a sustentabilidade da produção, em função da disponibilidade de biomassa nas propriedades agrícolas, por apresentar baixo custo de oportunidade dos resíduos da produção, grande potencial de geração de energia, diminuição no potencial poluidor dos resíduos, redução na pressão sobre os recursos naturais e economia de recursos energéticos (ANGONESE et al., 2006).

Souza et.al. (2006), analisando economicamente o uso do biogás da bovinocultura e o aproveitamento da energia na irrigação, para uma tarifa de RS 190,00 $\mathrm{MWh}^{-1}$, observaram que os tempos de retorno do capital, considerando o desconto da taxa de juros, foi de 8,5 e 4 anos para períodos de geração diária de 4 e $10 \mathrm{~h}$, respectivamente.

Martins e Oliveira (2011), no estudo sobre a análise econômica da geração de energia elétrica a partir do biogás da suinocultura, demonstraram a viabilidade econômica da geração de energia elétrica com o uso do biogás gerado a partir da digestão anaeróbia de dejetos de suínos. Embora seja possível a comercialização, os resultados demonstram que é mais vantajoso economicamente o uso desta energia na propriedade rural, substituindo ou reduzindo a aquisição da energia elétrica distribuída pela concessionária.

Já Stokes et al. (2008), na análise da geração de energia a partir da biodigestão de resíduos proveniente da bovicultura no Estado da Pennsylvania, nos Estados Unidos, no qual foram simulados diferentes cenários de uso e comercialização da energia elétrica gerada, além da utilização do biofertilizante gerado, em que o investimento total do sistema de geração de energia foi de R \$ 593.015,00 (US\$ 311.000,00), sendo que o mesmo obteve geração elétrica anual de 665.000 $\mathrm{kWh}^{-1}$.

Diante deste contexto objetivou-se realizar um estudo de viabilidade econômica e estimativa da produção do biogás como fonte alternativa para a geração de energia elétrica a ser utilizada no Perímetro Irrigado Quixabinha, em Mauriti - CE.

\section{MATERIAL E MÉTODOS}

No presente trabalho, primeiramente, foi realizado uma pesquisa na literatura sobre geração de energia elétrica por meio de biogás e estudo do Perímetro Irrigado, para o conhecimento da biomassa disponível para a geração do mesmo e, consequentemente, do potencial para geração de energia elétrica.

O trabalho foi realizado no Perímetro Irrigado de Quixabinha, localizado no município de Mauriti CE, região do Cariri, no Vale do Rio dos Porcos, subvale do Rio dos Bois, cujas coordenadas geográficas são $7^{\circ} 30^{\prime}$ de latitude e $38^{\circ} 45^{\prime}$ de longitude. A análise do perímetro se deu, pois, além dos resíduos vegetais, existe a possibilidade de utilização dos resíduos de animais, devido à atividade da bovinocultura existente no perímetro

De acordo com Oliveira et al. (2012), o Distrito de Irrigação Quixabinha possui uma área total de 530,35 ha, onde 293,35 ha são áreas de sequeiro, e o restante, 293 ha, são áreas irrigáveis por sistema de irrigação por aspersão convencional. No entanto, a sua importância econômica está na diversidade de culturas produzidas no perímetro 
de alto valor agregado como banana, coco, uva, algodão herbáceo, e culturas de subsistências, como feijão e milho, além da criação de bovinos.

Para a estimativa do potencial de geração de energia a partir de resíduos agrícolas, foram levados em conta os valores das produções agrícolas em cada cultura, onde foram consideradas seis culturas (banana, coco, uva, algodão, milho e feijão), utilizando uma área de 280 hectares. Tem-se uma produção estimada de 1 tonelada anual de resíduos agrícolas cada cultura, proveniente das frutas e dos vegetais, totalizando assim um valor de $6.000 \mathrm{~kg}$ ano $^{-1}$.

Com relação aos bovinos, foram consideradas 60 cabeças de bovinos, criados pelos agricultores familiares do Perímetro Irrigado Quixabinha, onde cada animal produz em média $25,2 \mathrm{~kg}$ de resíduos por dia. Tem-se, assim, uma produção anual de $544.320 \mathrm{~kg}$ de resíduos.

A inserção dos valores no software RETScreen ${ }^{\circledR}$, estimou a produção de biogás, a viabilidade econômica e a capacidade de geração de energia elétrica no Perímetro Irrigado, utilizando os restos vegetais das culturas e os resíduos dos bovinos.

O Perímetro Irrigado de Quixabinha foi considerado para a estimativa da análise econômica por apresentar alto potencial de produção de biomassa para geração de energia elétrica, pois os resíduos vegetais das próprias culturas cultivadas e, especificamente, dos resíduos da bovinocultura se constituem em uma matéria prima para a geração de biogás por meio dos biodigestores.

O biodigestor utilizado na simulação é o tipo tubular, modelo 4500 da marca recolast, com sistema pré-fabricado em geomembrana de PVC de $1 \mathrm{~mm}$, e lagoa de biofertilizante em manta de PVC de $0,80 \mathrm{~mm}$, composto por biodigestor tubular de $1,40 \mathrm{~m}$ de comprimento por $4,5 \mathrm{~m}$ de diâmetro, lagoa de biofertilizante escavada 3,6 m x 3,6 m x $1 \mathrm{~m}$, tubulação de entrada, saída, e limpeza, tubulação de biogás de $40 \mathrm{~mm}$ de diâmetro, manta geotextil de $3,25 \mathrm{~m} \times 8,5 \mathrm{~m}$, válvula de alivio e flare. O preço total do sistema, incluindo mão de obra e instalação, foi em torno de $\mathrm{R} \$ 3.450,00$.

$\mathrm{O}$ cálculo da geração de energia elétrica foi baseado em estudos realizados por Santos (2000), onde estipula que $1 \mathrm{~m}^{3}$ de biogás equivale a 6,5 $\mathrm{kWh}^{-1}$ de energia elétrica e a eficiência dos sistemas de geração varia entre 30 e 38\%, ou seja, 2,0 a 2,5 $\mathrm{kWh}^{-1}$, o que condiz com os resultados encontrados no estudo realizado por Coldebella et al. (2006) que foram de $32,3 \%$ de eficiência e $2,1 \mathrm{kWh}^{-1}$.

A tarifa da energia elétrica utilizado foi baseada nos valores do Quadro 1, na qual especifica o sistema de geração, a eficiência, e especificamente o investimento na tecnologia de geração, no caso especifico o biodigestor.

Considerou-se também como base para este trabalho uma estimativa do potencial de resíduos agrícolas dos municípios da região Nordeste, realizado pelo Centro Nacional de Referência em Biomassa-CENBIO em 2012, mostrados na Figura 1. Para compreender os cálculos de conversão energética dos diversos tipos de biomassa, foram estabelecidas diferentes tecnologias de conversão e considerados os respectivos poderes caloríficos de cada biomassa.

O estudo foi baseado no aproveitamento do biogás gerado pelos resíduos produzidos no sistema de produção das culturas e da bovinocultura, conforme o fluxograma apresentado na Figura 2. Por meio do software RETScreen ${ }^{\circledR}$, foi possível realizar a simulação da quantidade de biogás necessário gerado a partir dos resíduos vegetais das culturas e dos animais, para o processo de biodigestão. $\mathrm{O}$ biogás obtido foi aplicado às turbinas a gás para obtenção de energia elétrica.

Quadro 1. Estimativas econômicas e tecnologias de geração distribuída.

\begin{tabular}{lcccc}
\hline $\begin{array}{c}\text { Sistema de } \\
\text { geração }\end{array}$ & $\begin{array}{c}\text { Energia } \\
\text { primária }\end{array}$ & $\begin{array}{c}\text { Eficiência de } \\
\text { geração }(\%)\end{array}$ & $\begin{array}{c}\text { Investimento (US\$/ } \\
\mathrm{kW})\end{array}$ & $\begin{array}{c}\text { Custo da Energia (US\$/ } \\
\text { MWh) }\end{array}$ \\
\hline Turbina a Gás & Biogás & 26 a 60 & 550 a 2.500 & 75 a 115 \\
PCH & Água & 80 a 90 & 550 a 4.500 & 70 a 275 \\
Eólica & Vento & 43 & 1.000 a 3.000 & 95 a 140 \\
\hline
\end{tabular}

Fonte: EC (2008). 


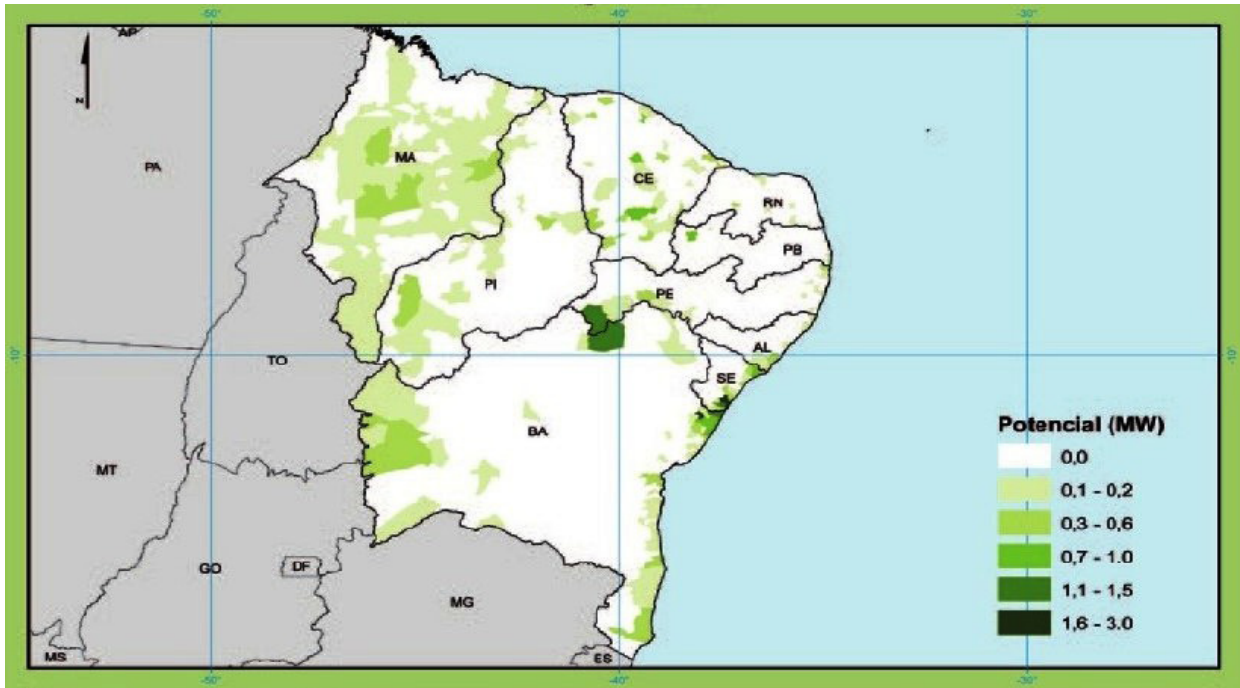

Fonte: Coelho et al. (2012).

Figura 1. Estimativa do potencial de geração a partir do uso de resíduos agrícolas nos municípios da região Nordeste.

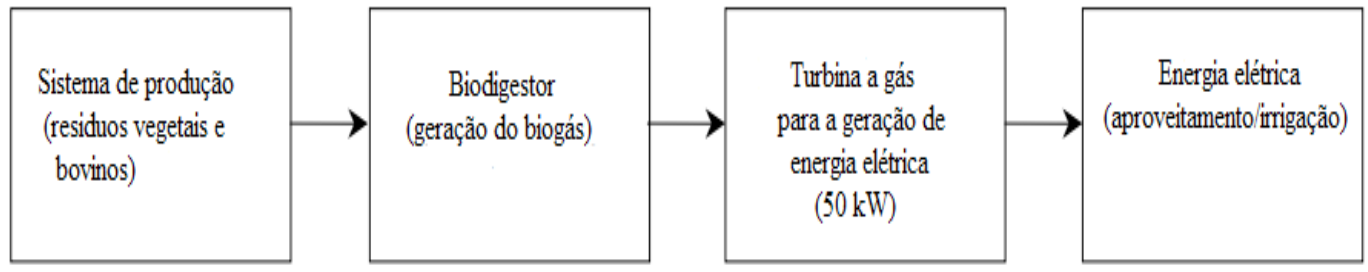

Figura 2. Fluxograma do processo de obtenção do biogás para geração de energia elétrica.

O RETScreen ${ }^{\circledR}$ é um software de análise de projetos de energia limpa, um dos mais avançados softwares de suporte à tomada de decisão no setor de energia limpa. O mesmo é totalmente livre de custos para estudantes, disponibilizado pelo Governo do Canadá, e é um comprovado ativador de projetos de energia limpa em todo o mundo, apoiando a decisão de investimento em energias renováveis, adotado mundialmente por peritos do governo, indústria, e pela academia, (RETScreen $\left.{ }^{\circledR}, 2014\right)$. Autores como Altoé e Oliveira Filho (2010) e Dutra e Tolmasquim (2002) também utilizaram o RETScreen ${ }^{\circledR}$ em seus trabalhos.

\section{RESULTADOS E DISCUSSÃO}

Na Figura 3 pode-se observar a produção de biogás calculada por meio do RETScreen ${ }^{\circledR}$ que foi de $3.030 \mathrm{~m}^{3}$ ano $^{-1}$, sendo o total de biogás produzido utilizado diretamente no sistema de conversão de energia elétrica para determinação do potencial de geração de energia, considerando o funcionamento do sistema de 7,3 $\mathrm{h} \mathrm{dia}^{-1}$, em média, ficando o restante de horas do dia para eventuais manutenções. Assim, foi estimado um período de 30 dias por mês durante todo o ano, que resultou em $2.628 \mathrm{~h}$ de operação por ano.

Vale ressaltar que a produção de biogás depende diretamente da disponibilidade de resíduos (animal e/ou vegetal), e das condições de manutenção e operação do biodigestor, ou seja, do sistema como um todo.

Cervi et al. (2010), em seu trabalho com relação a viabilidade econômica da utilização do biogás produzido em granja suínícola para geração de energia elétrica, obtiveram uma produção de biogás de $670.760,5 \mathrm{~m}^{3}$ ano $^{-1}$, o sistema funcionando 10,5 $\mathrm{h}$ dia $^{-1}$, em média, com exceção de domingos e 


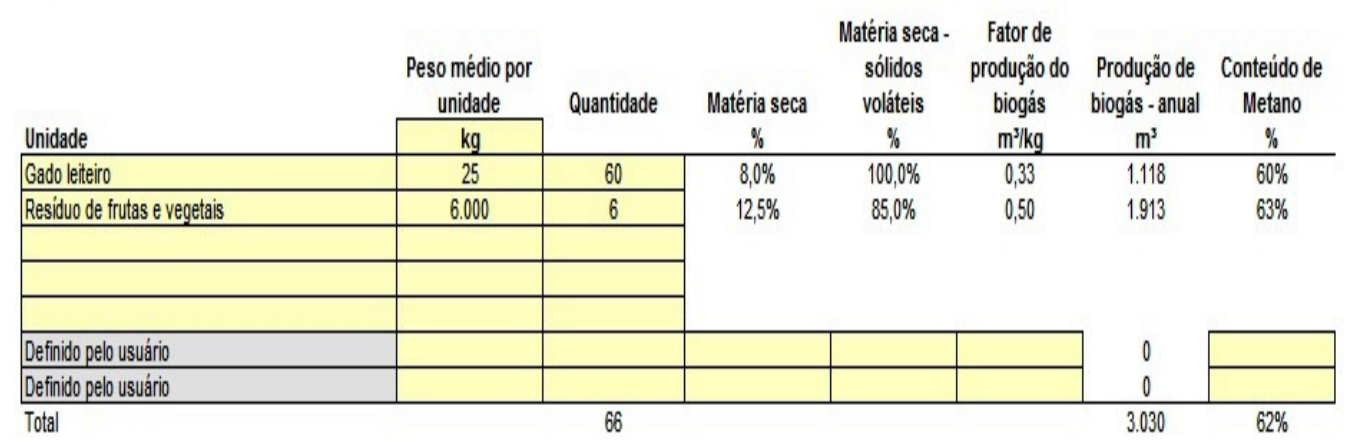

Figura 3. Produção anual de biogás estimada no Perímetro Irrigado Quixabinha

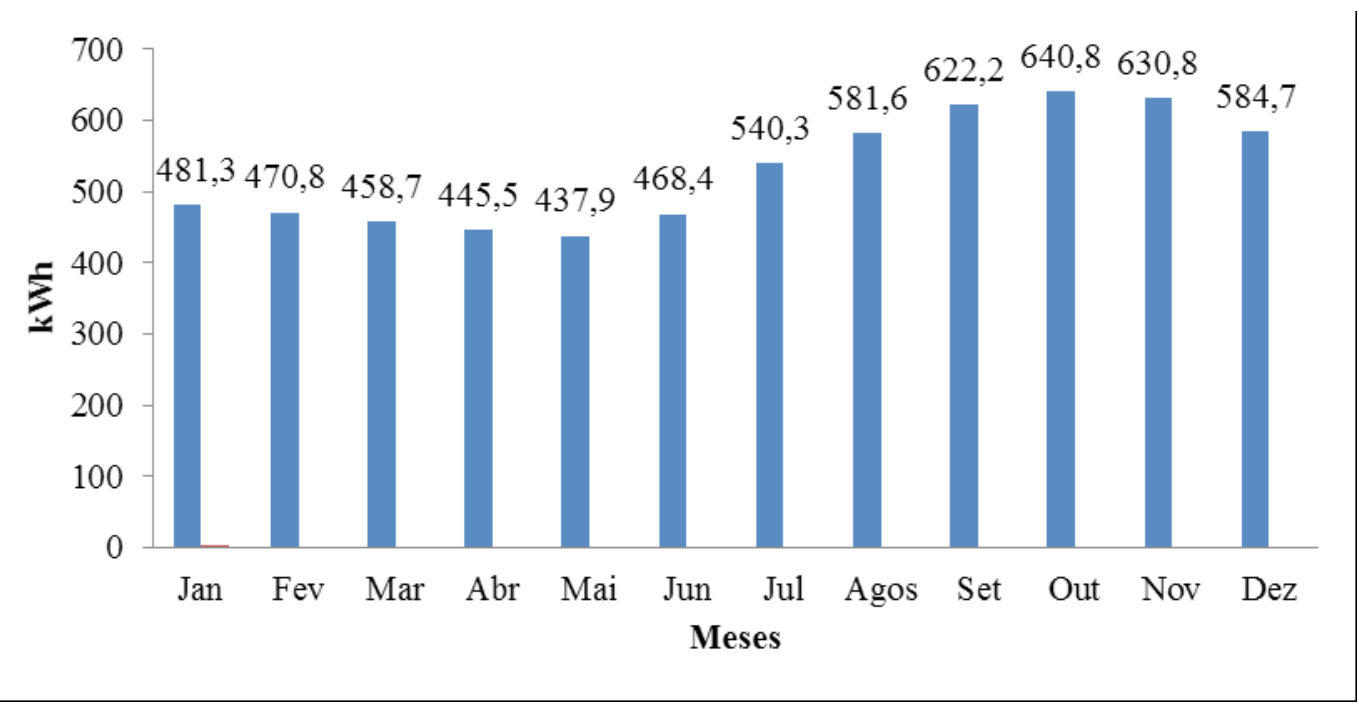

Figura 4. Capacidade de geração de energia elétrica proveniente do biogás.

feriados, durante um período de 26 dias por mês e 312 dias de operação por ano, o que resultou em $3.276 \mathrm{~h}$ de operação por ano.

Vale salientar que o biodigestor pode operar durante o ano inteiro, sob condições adequadas de operação e manutenção do mesmo, e que quanto maior for o tempo de operação, menor o custo de geração de energia elétrica, diminuindo, com isso, o tempo de retorno do investimento, considerando sempre a quantidade de biomassa e as operações de manutenções.

$\mathrm{Na}$ Figura 4, observa-se a capacidade de geração de energia elétrica no Perímetro Irrigado Quixabinha, proveniente do biogás oriundo dos restos vegetais das culturas e resíduos dos animais. Com um volume de biogás de $3.030 \mathrm{~m}^{3}$ ano $^{-1}$, se obtém a capacidade de gerar anualmente $6.363 \mathrm{kWh}^{-1}$ de energia elétrica, de acordo com a equivalência de conversão energética de $1 \mathrm{~m}^{3}$ de biogás, equivalente a $2,1 \mathrm{kWh}^{-1}$ de energia elétrica, com eficiência de 32,3\%. Na Figura 4 está representada a geração de energia elétrica por mês, em que a média mensal corresponde a $530,25 \mathrm{kWh}^{-1}$.

Outro ponto interessante observado é que no primeiro semestre do ano, têm-se valores de geração de energia menores, o que coincide com uma menor demanda energética do Perímetro Irrigado, pois é o período onde há maior precipitação pluviométrica na região, não necessitando de acionamentos do sistema de irrigação com frequência. Porém, quando se observa o segundo semestre, há um aumento significativo nos valores de gerações de energia elétrica pelos sistemas de biodigestores, que corresponde ao período de maior consumo de energia elétrica no Perímetro. Isso é facilmente justificado devido às condições de temperatura a que os biodigestores são submetidos, onde, no período chuvoso, têm-se temperaturas menores, o que

\section{REVENG}


dificulta a atuação das arqueias metanogênicas no processo de biodigestão da biomassa, produzindo, assim, menos metano, e consequentemente, diminuição do biogás.

Conforme Santos (2000), a produção de biogás está diretamente relacionada à temperatura, pois a mesma influência na digestão anaeróbia afetando os processos relacionados à atividade biológica dos microrganismos envolvidos. A temperatura mais favorável ao crescimento dos microrganismos anaeróbios está na faixa dos $35^{\circ} \mathrm{C}$, para temperaturas abaixo dos $25^{\circ} \mathrm{C}$, a velocidade de digestão decresce acentuadamente, reduzindo a produção de biogás. Levando em consideração o fator temperatura, o valor de produção de biogás pode sofrer alterações, principalmente nos meses de inverno, onde a produção é menor.

Oliveira (2008) menciona que o biodigestor deve atender uma série de pré-requisitos, a fim de garantir o ambiente propício para uma adequada produção de biogás. Deve-se efetuar a vedação completa para evitar a entrada de oxigênio e com isso possibilitar a criação das arqueias metanogênicas, responsáveis pela digestão dos dejetos, um pH não ácido, o que significa níveis acima de 7 , temperatura entre $28^{\circ} \mathrm{C}$ e $35^{\circ} \mathrm{C}$, pois os micro-organismos produtores de metano são muito sensíveis a variações de temperatura, sendo preciso assegurar a sua estabilidade, seja através do aquecimento interno ou de melhor isolamento térmico da câmara de digestão durante os meses de inverno.

Com relação à viabilidade econômica, no que se refere à taxa interna de retorno e o período de retorno do investimento, na Figura 5 observa-se os valores econômicos para a geração de energia elétrica por meio do biogás no Perímetro Irrigado Quixabinha com uma TIR de 32,1\% e um payback de 3,2 anos para o caso simulado. Resultados semelhantes foram observados por Esperancini et al. (2007), onde, analisando a viabilidade de implantação de dois biodigestores em assentamentos rurais com uso de dejetos animais, um para o fornecimento de energia para os domicílios e outro para as atividades produtivas, obtiveram um período de recuperação do investimento de 2,5 anos e 11 meses, para a utilização de biogás nos domicílios e nas atividades de produção, respectivamente.

Junges et al. (2009) realizaram um estudo sobre a análise econômico-financeira da implantação de diferentes modelos de biodigestores em duas propriedades (A e B), no município de Toledo no -PR. Os autores apontaram que a grande quantidade de dejetos viabilizaram a implantação de biodigestores porque gerava maior produção de biogás, maior economia de energia elétrica e créditos de carbono.

Um fator importante a considerar no sistema

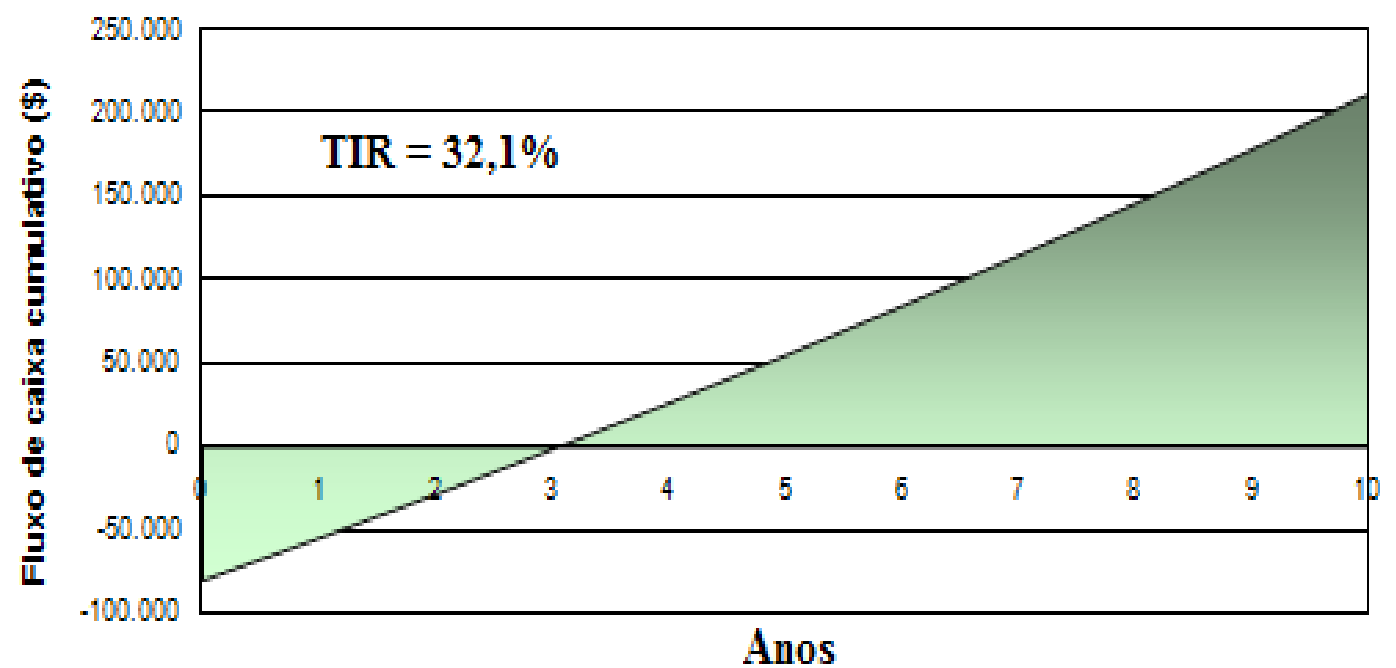

Figura 5. Viabilidade econômica do uso biogás para a geração de energia elétrica no Perímetro Irrigado Quixabinha. 
de utilização do biogás para fins energéticos, bem como a introdução de outros sistemas de geração de energias renováveis na agricultura irrigada, e que o mesmo se constitua em viabilidade econômica, são os subsídios, uma vez que o sistema proposto é inserido na agricultura familiar, onde o auxilio governamental é fundamental para a inserção das tecnologias no meio rural.

\section{CONCLUSÃO}

- A partir das simulações realizadas, o sistema mostrou-se viável do ponto de vista econômico. Pode-se afirmar que a produção de biogás para a produção de energia elétrica torna-se uma alternativa interessante para a diminuição da dependência de energia elétrica da concessionária para o Perímetro Irrigado Quixabinha;

- A inserção de novas fontes de geração de energia com aproveitamento do potencial local é uma alternativa pertinente dentro da ótica de desenvolvimento sustentável.

\section{REFERÊNCIAS BIBLIOGRÁFICAS}

ANA. Projeto de Gerenciamento Integrado das Atividades na Bacia do São FranciscoANA/GEF/ PNUMA/OEA. Subprojeto 4.5C - Plano Decenal de Recursos Hídricos da Bacia Hidrográfica do Rio São Francisco - PBHSF (2004-2013). Estudo Técnico de Apoio ao PBHSF - No 12 Agricultura Irrigada. Brasília, Distrito Federal; 2004.

ANGONESE, A.; CAMPOS, A.T.; ZACARKIM, C.E. Eficiência energética de sistema de produção de suínos com tratamento dos resíduos em biodigestor.

Revista Brasileira de EngenhariaAgrícola e Ambiental, Campina Grande, v.10, n.3, p.745750, jul./set. 2006.

ALTOE, L.; OLIVEIRA FILHO, D.Utilização de sistemas fototérmicos com concentradores para higienização de salas de ordenha.Revista Engenharia Agrícola. v.30, n.5, pp. 799-810. 2010.
BARRERA, P. Biodigestores: energia, fertilidade e saneamento para zona rural. São Paulo: Ícone, 2003. 106p.

COLDEBELLA, A. Viabilidade do uso do biogás da bovinocultura e suinocultura para geração de energia elétrica e irrigação em propriedades rurais. 2006. 73f. Dissertação (Mestrado em Engenharia Agrícola / Engenharia de Sistemas Agroindustriais) - Universidade Estadual do Oeste do Paraná, Cascavel, 2006.

CERVI, R.G.; ESPERANCINI, M.S.T.; BUENO, O.C. Viabilidade econômica da utilização do biogás produzido em granja suinícola para geração de energia elétrica. Revista Engenharia Agrícola. Jaboticabal, v.30, n.5, p.831-844, set./out. 2010.

COELHO, S.T.; MONTEIRO, M.B.; KARNIOL, M.R. Atlas de Bioenergia do Brasil: Projeto Fortalecimento Institucional do CENBIO - Centro Nacional de Referência em Biomassa. Universidade de São Paulo. 2012.

DUTRA, R.M.; TOLMASQUIM, M.T. Estudo de viabilidade econômica para projetos eólicos com base no novo contexto do setor elétrico. RevistaBrasileiradeEnergia.v.9. n.1. 10 Nov. 2013.

ESPERANCINI, M.S.T.; COLEN, F.; BUENO, O.C.; PIMENTEL, A.E.B.; SIMON, E.J. Viabilidade técnica e econômica da substituição de fontes convencionais de energia por biogás em assentamento rural do Estado de São Paulo. Revista Engenharia Agrícola, Jaboticabal, v.27, n.1, p.110-118, 2007.

European Comission - EC. Energy sources, production costs and performance of technologies for power generation, heating and transport. Bruxelas. 2008.

JUNGES， D.M.; KLEINSCHMITT, S.C.; SHIKIDA, P.F.A.; SILVA, J.R. Análise econômico-financeira da implantação do sistema de biodigestores no Município de Toledo (PR). Revista de Economia. Curitiba, v.35, n.1, p.7-30, jan-abr. 2009. 
LARA. M. Perímetros de irrigação pública respondem por menos de $10 \%$ da área irrigada no Brasil. 2010. Disponível em $<$ www.canalrural. com.br/canalrural/jsp/default.jsp?uf=1\&loc $>$, Acesso em: 08 maio. 2014.

MARTINS, F.M.; OLIVEIRA, P.A.V. Análise econômica da geração de energia elétrica a partir do biogás na suinocultura. Revista Engenharia Agrícola. Jaboticabal, v.31, n.3, p.477-486, maio/ jun. 2011.

ONS - Operador Nacional do Sistema Elétrico. Boletim Técnico de Previsão e Acompanhamento da Carga. Rio de Janeiro: ONS, 2011. v. 1. n. 2. Disponível em: <http://www.ons.org.br/download/ operacao/previsao_carga/Boletim $\% 20$ Tecnico $\% 20$ Previsao $\% 20 \mathrm{Carga} P 1$ anejamento $\% 20$ Energ\%C3\%A9tico\%202012-2016.pdf>. Acesso em: 12 janeiro. 2014.

OLIVEIRA， F.A.; ALBUQUERQUE， J.A.; GADELHA, W.S. Potencialidades dos perímetros irrigados do DNOCS. Fortaleza, escritório técnico de estudos econômicos do Nordeste, 199p. 2012.

OLIVEIRA, P.A.V. Projeto de biodigestor para produção de biogás em sistema de produção de suínos. 2008. Disponível em: $<$ http://. www. cnpsa.embrapa.br/down.php?tipo=artigos\&cod artigo $=263>$. Acessoem: 12 maio. 2014.

RETScreen ${ }^{\circledR}$ International Clean Energy Project Analysis Software. RETScreen ${ }^{\circledR}$ International Clean Energy Decision Support Centre. (2004). Clean Energy Project Analysis: RETScreen ${ }^{\circledR}$ Engineering \& Cases Texbook. Disponível em: $<$ www.retscreen.net.> Acesso em: 10 maio. 2014.

SANTOS, P. Guia técnico de biogás. Portugal: Centro para a Conservação de Energia, 117p 2000.

SOUZA, S.N.M.; COLDEBELLA, A.; SOUZA, J.; KOEHELER, A.C. Viabilidade econômica de uso de biogás da bovinocultura para geração de eletricidade e irrigação. In: CONGRESSO BRASILEIRO DE ENGENHARIA AGRÍCOLA, 35., 2006, João Pessoa. Anais... Jaboticabal: Associação Brasileira de Engenharia Agrícola, CD-ROM. 2006.

STOKES, J.R.; RAJAGOPALAN, R.M.; STEFANOU, S.P. Investment in a methane digester: An application of capital budgeting and real options. Review of agricultural economics, Amsterdam, v.30, n.4, p.664-676, 2008. 